\title{
Caminhos do Licenciado em Computação no Brasil: Estudo de Mercado a Partir de uma Pesquisa com Egressos
}

\author{
Achiles P. da C. Luciano ${ }^{1}$, Adriano Araújo Santos ${ }^{2,3}$ \\ ${ }^{1}$ Departamento de Computação - Universidade Estadual da Paraíba - Campina Grande, \\ PB - Brasil \\ ${ }^{2}$ Programa de Pós-graduação em Ciência da Computação - Universidade Federal de \\ Campina Grande (UFCG) - Campina Grande, PB - Brasil, \\ ${ }^{3}$ Professor do Curso de Sistemas de Informação - CESED/FACISA - Campina Grande, \\ PB - Brasil \\ \{achilespcluciano@gmail.com, adriano@copin.ufcg.edu.br\}
}

\begin{abstract}
The technological changes in society influenced the school, developing in it the shortage of a professional, degree in computer science, capable of to aid the learning through computer use. The controversial discussions concerning this professional motivated the development of a scientific research which aims to provide a statistical basis to expand the discussions about their role in Brazil, from the pathways taken by graduates of the courses. This study intends to report the initial results of the research. They point to the high level of professional satisfaction, the main areas of expertise and perspectives identified through data mining tests.
\end{abstract}

Resumo. As transformações tecnológicas na sociedade influenciaram a escola, desenvolvendo nela a carência de um profissional, licenciado em computação, capaz de veicular a aprendizagem por meio do uso do computador. As polêmicas discussões acerca deste profissional motivaram a elaboração uma pesquisa cientifica que objetiva fornecer base estatística para ampliar as discussões acerca do seu papel no Brasil, a partir dos caminhos trilhados pelos egressos dos cursos. Este trabalho pretende relatar os resultados iniciais da pesquisa. Eles assinalam o alto nível de satisfação dos profissionais, as principais áreas de atuação e perspectivas apontadas por meio de testes de Mineração de Dados.

\section{Introdução}

As relações existentes entre humanos e computadores se modificaram com o passar das décadas. Catalisador de mudanças sociais, o computador deixou de ser apenas uma máquina cujas funcionalidades se limitavam ao auxílio em cálculos numéricos complexos e decodificação de mensagens criptografadas, tornando-se, agora, ambiente de compartilhamento e interatividade. Mais do que uma simples automatização de capacidades físicas, os computadores estabeleceram-se como próteses cognitivas [Seabra 2010], modificando nossas formas de pensar, agir e interagir [Moita 2007], virtualizando uma sociedade em rede, cuja principal moeda é a informação. 
Autores como Moran (2007), Veen e Vrakking (2009), Valente (s.d.), e Tajra (2008), apontam os benefícios do uso dos computadores no cenário educacional, como alternativa para transpor os limites físicos da sala de aula e potencializar o processo de ensino e aprendizagem. $\mathrm{O}$ uso de softwares educacionais, jogos eletrônicos, simuladores, tutoriais, vídeo-aulas, linguagens de programação, e outros, torna-se valiosa ferramenta em sala de aula, criando um ambiente dinâmico e fortalecedor de conceitos estudados. Meneses (2011), afirma que a apropriação da tecnologia na prática pedagógica é fator decisivo para a inserção da escola nesse "novo mundo".

No Brasil, de acordo com Moraes (1997) e Tavares (2002), as discussões acerca do uso da informática na educação iniciaram-se na década de 70 e culminaram, já na década de 80, na criação de programas como o Projeto EDUCOM, e o Programa Nacional de Informática Educativa (PRONINFE), que, a partir da incorporação de outros projetos, deu origem ao Programa Nacional de Informática na Educação (PROINFO), em 1997.

Além da implantação de laboratórios de informática nas escolas públicas do país, dados da Secretária de Educação Básica do Ministério da Educação (MEC) do Brasil constam que foram distribuídos 147,5 mil classmate pc's, para 179 municípios [Cornils, 2011] e adquiridos 5 mil unidades de tablets, usadas em cursos de formação de coordenadores e de multiplicadores.

Apesar do investimento aplicado, a estrutura criada parece não ser o suficiente. Restam críticas à metodologia empregada quanto ao uso dos computadores em sala de aula. A mera informatização dos recursos tradicionais de ensino parece apenas potencializar a sua desconexão do contexto atual, caracterizado pela necessidade de formar indivíduos capazes de perceber as mudanças da sociedade e apreender metodologias eficazes para lidar com estas mudanças. Para Lampert (2001, p.61) "o computador, que ao mesmo tempo deve ser superestimado e subestimado, não é uma panacéia que irá resolver todos os problemas do ensino".

Entre os problemas apontados, Priecht e Pazeto (2009), relatam a carência de um profissional que seja capaz de promover o ensino de computação nas escolas e intermediar, por meio de projetos interdisciplinares o uso das ferramentas tecnológicas, especificamente o computador, em sala de aula.

A fim de suprir a necessidade deste profissional, no ano de 1997, a Universidade de Brasília criou o primeiro curso de Licenciatura em Computação no Brasil, com o objetivo de formar um profissional habilitado para lidar com as transformações tecnológicas e mediar o aprendizado por meio do uso do Computador. Dez anos depois, em 2007, segundo pesquisa realizada por Silva e Pietrich (2008), já haviam 58 instituições que ofertavam o curso.

A fim de avaliar os caminhos trilhados pelo aluno do curso de Licenciatura em Computação após a conclusão do curso, realizou-se uma pesquisa, no estado da Paraíba, para analisar as oportunidades do mercado, identificar problemas, inferir sobre as expectativas de um currículo que corresponda ao que perfil do profissional e fornecer base estatística para ampliar as discussões acerca do papel do licenciado em Computação no Brasil. 
Para isto, foi elaborado e distribuído um questionário para egressos dos cursos, e criado um conjunto de relações, por meio de técnicas de mineração de dados. A partir daí, surgem os primeiros resultados quantitativos e qualitativos que suportam, entre outras afirmações, que todos os participantes estão empregados e a maioria possui remuneração superior à média nacional.

\section{Apontamentos para o perfil do Licenciado em Computação}

De acordo com a $\mathrm{SBC}^{1}$ a Licenciatura em Computação almeja a formação profissional docente, e engloba conhecimentos pertinentes à área de Sistemas de Computação e suas aplicações. O campo de atuação do profissional licenciado em computação abrange a educação básica nas escolas, as séries finais do ensino fundamental e o ensino de nível médio, assim como a educação profissional. Além disso, os egressos do curso devem compreender os fundamentos da Ciência da Computação e promover o desenvolvimento científico na área de sua especialidade. Contudo, ainda não há concursos públicos suficientes para suprir a oferta de profissionais gerada pelo curso. Em uma pesquisa relacionada à evasão dos alunos em um curso de Licenciatura em Informática, Prietch e Pazeto (2010) apontam como um dos motivos citados por alunos a falta de mercado de trabalho.

Oliveira (2005) realizou uma pesquisa de campo junto à primeira turma de formandos de um curso de Licenciatura em Computação no estado do Mato Grosso. O objetivo era averiguar as intenções do alunado ao ingressar no curso e se as concepções adquiridas no decorrer do curso eram compatíveis com as primeiras aspirações. A pesquisa procurou, também, investigar as expectativas dos egressos acerca do mercado de trabalho.

Os resultados da pesquisa apontaram que os egressos, no período de ingresso na faculdade, não estavam cientes das habilidades que seriam desenvolvidas durante o curso. Porém, no decorrer da formação, a maioria dos acadêmicos pesquisados $(86,67 \%)$, conscientizou-se acerca dos aspectos da formação docente. Quanto às expectativas junto ao mercado de trabalho, apenas $60 \%$ dos participantes demonstraram otimismo. A falta de amparo do governo para inserir o licenciado em Computação nos projetos de inclusão digital das escolas foi novamente apontada.

Prietch e Pazeto (2010) realizaram um mapeamento dos cursos de Licenciatura em Computação no Brasil e propuseram uma matriz curricular capaz de promover, nos egressos, as habilidades adequadas para a atuação do egresso no mercado de trabalho.

Nascimento (2010) investigou o perfil da primeira turma de formandos do curso de Licenciatura em Computação da Universidade Estadual da Paraíba, Campus VII na cidade de Patos, Paraíba. Sua pesquisa investigou o perfil sócio-cultural dos participantes, as opiniões dos concluintes acerca da estrutura do curso, procurando identificar dificuldades encontradas no decorrer do curso e falhas no processo metodológico de ensino, além de analisar o projeto político-pedagógico do curso e as expectativas dos participantes no tocante ao mercado de trabalho em que atuariam.

\footnotetext{
1 Currículo Referência para Cursos de Licenciatura em Computação, SBC, 2002. Disponível em: $<$ http://www.sbc.org.br/index.php?option=com jdownloads\&task=view.download\&catid=36\&cid=184\&I temid $=195>$. Acessado em 01/08/2013
} 
A discussão acerca do perfil profissional do licenciado em Computação parte dos princípios de atuação deste profissional no âmbito escolar. Sette et al (1997) indagava: "Licenciatura em Computação, por quê, para quem e para quê?", criticando a criação de um profissional cujas habilidades poderiam, teoricamente, ser supridas pelos docentes de disciplinas já estabelecidas, como Matemática e Física. Estas críticas são rebatidas, mas representam a necessidade de se ampliar os debates e padronizar as matrizes curriculares do curso no país.

As pesquisas desenvolvidas acerca da Licenciatura em Computação no Brasil ainda apresentam resultados relacionados ao currículo adotado pelas universidades e às expectativas dos alunos concluintes, restando uma análise objetiva acerca da atuação deste profissional quando inserido no mercado de trabalho, as dificuldades encontradas, a satisfação acadêmica e profissional e aspectos relacionados à empregabilidade na área de formação. A presente investigação tem o intuito de auxiliar a análise destes fatores.

\section{Aspectos Metodológicos da Pesquisa}

O público-alvo escolhido para a investigação foi os egressos do curso de Licenciatura em Computação da Universidade Estadual da Paraíba. Esta pesquisa considerou o profissional egresso do como habilitado para atuar no mercado de trabalho em qualquer área cuja especialidade abranja conhecimentos de sistemas de computação e mediação pedagógica com o uso de ferramentas tecnológicas. A metodologia aplicada contou, ainda, com as etapas de elaboração e disponibilização de um questionário online, análise dos dados coletados e testes primitivos de correlação, utilizando técnicas de mineração de dados.

Durante a primeira etapa da pesquisa, foram procurados alunos egressos do curso de Licenciatura em Computação do Campus I da Universidade Estadual da Paraíba. Através de contatos com a coordenação do curso e com a ajuda de alunos da instituição, o levantamento resultou na criação de uma lista com os nomes de 74 exalunos concluintes.

A partir de então, foi elaborado um questionário, com campos de identificação e questões relacionadas a aspectos acadêmicos e profissionais dos egressos. Procurou-se identificar a idade, naturalidade, áreas de atuação profissionais e acadêmicas, além de grau de satisfação com a formação e relato pessoal dos participantes acerca de suas opiniões quanto ao curso. Para facilitar a divulgação do questionário e agilizar a etapa de análise de dados, o questionário foi desenvolvido em plataforma online, utilizando a ferramenta Google Docs.

A coleta de dados foi necessária para que houvesse base estatística para inferir acerca da situação atual dos participantes e promover discussões sobre a atuação do licenciado em computação no mercado de trabalho. A partir dos dados coletados, foram feitos testes iniciais de mineração de dados para identificar fatores relevantes para a empregabilidade dos egressos. 


\section{Resultados e Discussão}

\subsection{Análise dos dados coletados}

A pesquisa alcançou 47 participantes, o equivalente a, aproximadamente, $64 \%$ da listagem obtida durante a etapa de levantamento.

Na primeira parte do questionário, procurou-se averiguar o sexo, a idade, a naturalidade e localidade atual de moradia dos participantes. A maioria respondeu ser do sexo masculino (77\%), com idade entre 21 e 35 anos (91\%), natural do estado da Paraíba (77\%), com residência atual no estado da Paraíba (92\%). Estes dados foram importantes para confirmação do público-alvo da pesquisa, já que, neste primeiro momento, procurase investigar a atuação dos egressos no estado da Paraíba.

Quanto às informações acadêmicas, a pesquisa se preocupou em questionar se os egressos prosseguiram com seus estudos, se participaram de programas de pósgraduação, e quais as áreas de suas atuações como pesquisadores. Os dados revelam que $66 \%$ dos respondentes participam ou participaram de programas de pós-graduação. Destes, a maioria possui especialização e/ou mestrado e/ou doutorado. A continuidade dos estudos aponta para as habilidades acadêmicas dos egressos, é um fator importante para o mercado de trabalho e acarreta produção de conhecimento para a sociedade. $\mathrm{O}$ gráfico a seguir detalha a participação dos egressos em programas de pós-graduação.

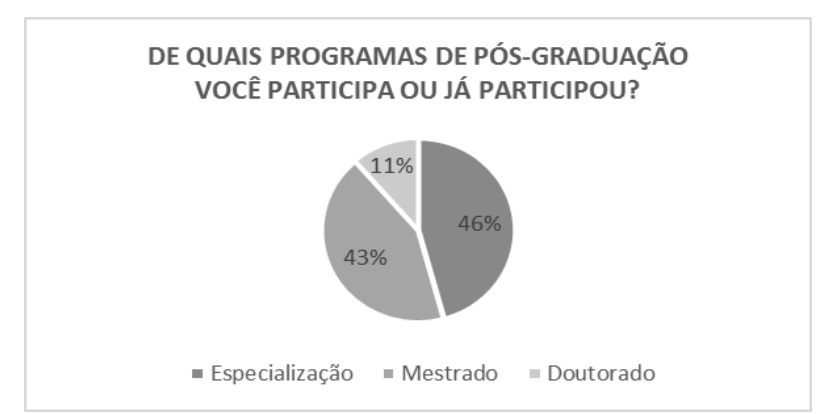

Figura 1. Participação dos egressos em programas de pós-graduação

A respeito da atuação dos participantes em áreas de pesquisa, apenas 3\% dos participantes afirmam não atuarem em qualquer área de pesquisa relacionada à tecnologia ou educação. As áreas de Informática na Educação, Jogos Educacionais e Educação à Distância apresentaram os maiores índices, com 23\%, 17\% e 16\%, respectivamente.

No campo "outros", foi aberto espaço para que os pesquisadores apontassem áreas de pesquisa de sua atuação que não estivessem listadas. Este campo obteve 13\% de respostas, nas quais foram apontadas pesquisas em Visão Computacional, Inteligência Artificial, Mineração de Dados Educacionais, M-Learning, Biossensores, Robótica Educativa, entre outras. Todas as respostas coletadas neste campo apontavam áreas de estudo pertinentes ao currículo de Licenciatura em Computação. 


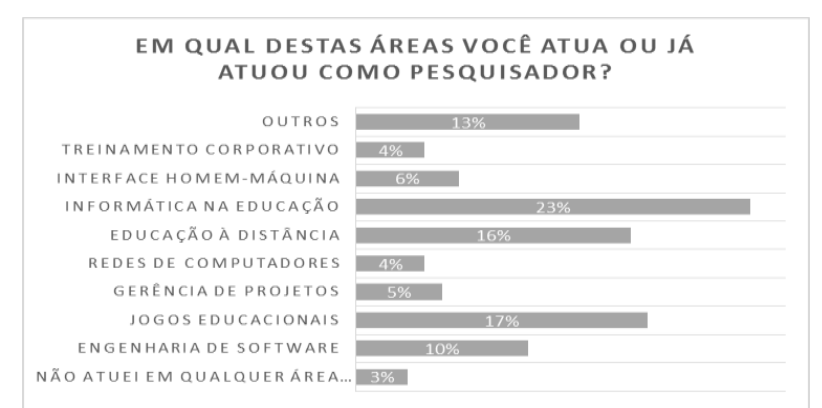

Figura 2. Áreas de atuação dos egressos como pesquisadores

A pesquisa ainda procurou investigar o perfil profissional dos participantes, com questões relacionadas à atual situação profissional, áreas de atuação no mercado, remuneração e satisfação com o trabalho. Os resultados obtidos apontam que nenhum dos participantes está desempregado, a maioria afirma ter remuneração acima de três salários, alguns, cerca de $28 \%$, ainda acima de quatro salários mínimos e o grau de satisfação com a profissão é alto, pois $73 \%$ dos respondentes afirmaram serem satisfeitos ou muito satisfeitos com a atividade atual. Os gráficos a seguir ilustram os resultados obtidos nesta investigação.

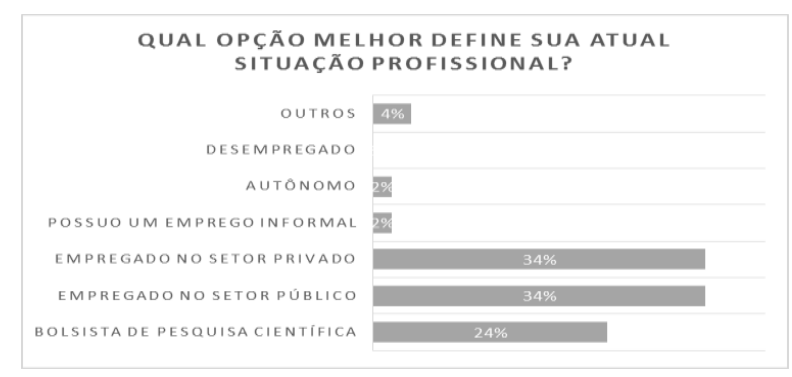

Figura 3. Situação profissional dos egressos

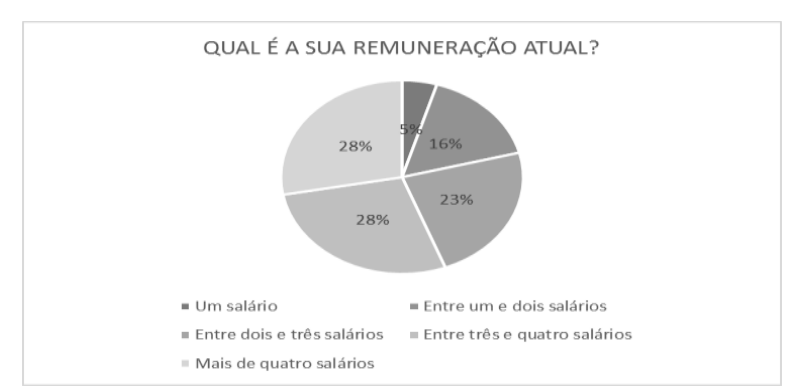

Figura 4. Gráfico de remuneração atual dos egressos

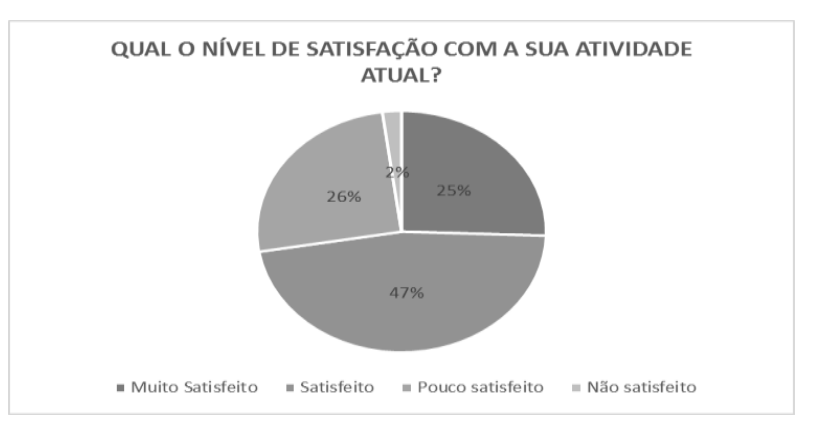

Figura 5. Níveis de satisfação dos egressos com sua formação 
Quanto às áreas de atuação profissional dos participantes, os dados apontam uma forte atuação na área educacional. A Educação Presencial e Educação à Distância alcançaram os maiores índices. Apenas $4 \%$ dos respondentes afirmam que não atuaram profissionalmente em qualquer área relacionada à educação ou tecnologia.

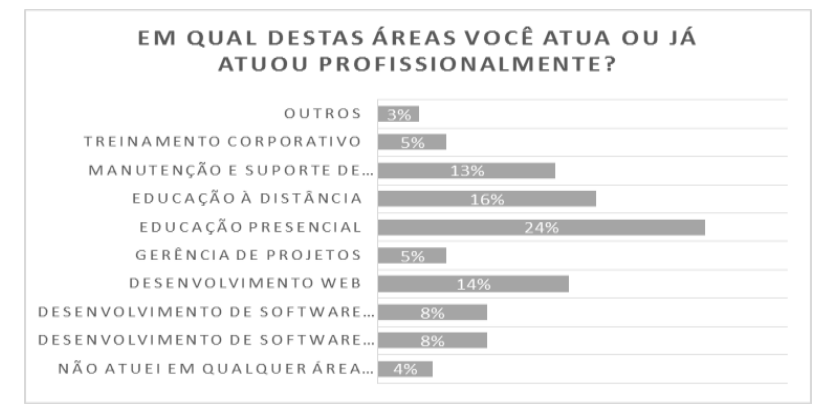

Figura 6. Áreas de atuação profissional dos egressos

Embora iniciais, estes resultados, levantam questionamentos passíveis de investigação. De acordo com a Pesquisa Mensal de Emprego ${ }^{2}$ (PME), realizada pelo IBGE, para o mês de junho de 2013, a taxa média de desemprego nas regiões metropolitanas foi de $6 \%$ e a média salarial $\mathrm{R} \$ 1.869,20$. Na pesquisa realizada com os egressos, o desemprego apontado é nulo e mais da metade dos participantes tem remuneração acima de três salários mínimos (mais de $\mathrm{R} \$ 2.034,00$ ), remuneração superior à média nacional. Entretanto, 36\% dos respondentes afirma estar pouco satisfeito ou insatisfeito com a sua formação. De acordo com as opiniões dos participantes, em um campo específico do questionário, a estrutura física do curso na época de sua formação, a falta de preparo pedagógico dos docentes e a escassez de vagas nas escolas públicas para o ensino de informática são fatores que prejudicam diretamente o aluno em formação.

\subsection{Avaliação de correlação estatística dos dados}

Com o intuito de analisar os resultados obtidos nesta pesquisa, foi realizado um experimento de mineração de dados cujo objetivo era investigar possíveis associações entre as respostas obtidas com o questionário.

Foram realizados dois ensaios com os dados, o primeiro com o algoritmo Apriori [Andrade 2007, p.52] e o segundo, baseado no algoritmo Tertius [Andrade 2007, p.56]. Ambos os algoritmos são de mineração de dados e os fatores selecionados para a observação foram: a) Pós-graduação (SIM ou NÃO), b) Satisfação com curso (Insatisfeito, Pouco Satisfeito, Satisfeito, Muito Satisfeito), c) Satisfação com trabalho (Insatisfeito, Pouco Satisfeito, Satisfeito, Muito Satisfeito), d) Relação formação e trabalho (SIM ou NÃO), Empregado (SIM ou NÃO) e, e) Remuneração (Não Informado, Um salário, Entre um e dois salários, Entre dois e três salários, Entre três e quatro salários, Maior que quatro). Para concluir, foi realizado um teste de regressão

\footnotetext{
2 Pesquisa Mensal de Emprego, IBGE. Disponível em: $<\mathrm{ftp}$ ://ftp.ibge.gov.br/Trabalho_e_Rendimento/Pesquisa_Mensal_de_Emprego/fasciculo_indicadores_ibg e/2013/pme_201306pubCompleta.pdf $>$. Acesso em 27/07/2013.
} 
linear a fim de obter a função objetivo da relação entre os fatores de satisfação com a formação, salário e pós-graduação.

O intuito inicial desta pesquisa é analisar se os egressos do curso de licenciatura em Computação estão trabalhando e se os trabalhos desempenhados por eles têm relação com a sua formação. Sabendo disso, por meio de mineração de dados, foram levantadas hipóteses. Hipótese 1: H0 - Os egressos não estão trabalhando. Ha - Os egressos estão trabalhando. Hipótese 2: H0 - Não existe relação entre os fatores observados. Ha Existe relação entre os fatores observados.

O teste Apriori analisa, em meio a um conjunto de dados, a existência de relação entre eles, extraindo regras. Com base nos fatores selecionados para análise, foram extraídas as dez melhores regras formando assim um conjunto de regras com confiança de $100 \%$.

Dentre as relações encontradas pelo algoritmo Apriori, destacam-se as relações "relacaoformacaotrabalho $=$ SIM $==>$ empregado $=$ SIM" e "posgraduacao $=$ SIM E relacaoformacaotrabalho $=$ SIM $==>$ empregado= SIM". Foi observado que as pessoas cujo trabalho está relacionado com a sua formação estão empregadas e que todos os participantes que continuaram suas atividades profissionais na área da sua formação, seguiram a carreira acadêmica por meio de alguma atividade de pós-graduação.

$\mathrm{O}$ algoritmo Tertius consiste em um algoritmo derivado da ideia inicial do algoritmo Apriori, porém ele faz uso de abordagens heurísticas como o objetivo de tornar a busca de regras mais eficientes [Andrade 2007, p. 56].

Com base nos resultados do teste Tertius, destacamos a regra "posgraduacao = $\mathrm{SIM}==>$ satisfacaocurso $=$ MuitoSatisfeito OU satisfacaotrabalho $=$ Satisfeito OU remuneracao = Maior que 4 salários". Foi possível observar que, se o participante é muito satisfeito com a sua formação, faz pós-graduação e é satisfeito com o seu trabalho, ele recebe o maior salário. Este resultado está de acordo com os resultados do teste Apriori.

Para concluir a análise dos dados, foram separados os fatores Salário, Especialização e Satisfação com a formação. Foi realizado um teste de regressão linear, a fim de obtermos a função matemática que representa a relação entre esses três fatores. Utilizando a classificação com cross-validation igual a 10, resultando na função a.

a) Salario $=0.6435 *$ Especializacao +2.5646

\section{Considerações Finais}

Com base em todas as análises realizadas sobre os dados da pesquisa, foi observado que os alunos egressos do curso de Licenciatura em Computação se encontram bem relacionados com o fator emprego até mesmo os que não deram continuidade em sua formação científica e que os que não trabalham com alguma atividade relacionada a sua formação. Nenhum dos participantes se encontra desempregado.

Uma característica que foi verificada é que, as pessoas que tem um nível alto de satisfação com o curso e que, também, deram continuidade à sua formação, se encontram com melhor remuneração. Sendo assim inferimos que não se trata, apenas, da 
qualidade do curso, mas a relação entre a qualidade do curso e a satisfação na escolha de uma formação em Licenciatura em Computação.

A continuidade desta investigação procurará identificar outras relações baseadas na satisfação de participantes, estabelecer contatos com outras instituições de formação em Licenciatura em Computação para coleta de dados e depoimentos de alunos e professores. O objetivo é estender a pesquisa nacionalmente, disponibilizar dados estatísticos para fomentar e ampliar as discussões acerca do profissional licenciado em Computação.

\section{Referências Bibliográficas}

Andrade, Alexandre A. de. (2007) Desenvolvimento de sistema especialista com operacionalidade de aprendizado para operar em tempo real com sistemas industriais automatizados. Tese (Doutorado em Sistemas de Potência) - Escola Politécnica, Universidade de São Paulo, São Paulo, 2007. Disponível em: http://www.teses.usp.br/teses/disponiveis/3/3143/tde-28032008-180226> Acesso em: 27/07/2013.

Cornils, P. (2011) “Um computador por aluno. Quando? Onde? Como?”. In: ARede, v. 7, n. 74, p. 10-17. Disponível em: < http://www.arede.inf.br/edicao-n-74-outubro2011/4896-capa-edicao-74>. Acesso em 27 de julho de 2013.

Lampert, E. (2001) “O Professor Universitário e a Tecnologia”. In: Galego-Portuguesa de Psicoloxía e Educacion, $\mathrm{n}^{\mathrm{o}} 5$ (vol. 7) 55-63. Disponível em http://ruc.udc.es/dspace/bitstream/2183/6735/1/RGP 5.7.pdf $>$. Acesso em 27 de julho de 2013.

Meneses, Soraya C. P. (2011) "UCA - Um Computador Por Aluno: Era Da Inclusão Digital". In: XXII Simpósio Brasileiro de Informática na Educação. SBC, Aracaju SE. Disponível em: http://www.br-ie.org/pub/index.php/sbie/article/view/1656/1421. Acesso em 27 de julho de 2013.

Moita, F. Ma G. S. C. (2007) "Game on: jogos eletrônicos na escola e na vida da geração @). Campinas: Editora Alínea.

Moraes, Maria C. (1997) "Informática Educativa no Brasil: uma história vivida, algumas lições aprendidas". In: Revista Brasileira de Informática na Educação, Florianópolis, n.1, p. 19-44. Disponível em: $<\underline{\text { http://www.br- }}$ ie.org/pub/index.php/rbie/article/view/2320/2082>. Acesso em 27 de julho de 2013.

Moran, J. M., Masetto, M. T. e Behrens, M. A. (2007). Novas Tecnologias e Mediação Pedagógica. Sao Paulo: Papirus Editora.

Nascimento, J. W. S. (2010) Perfil dos alunos formandos da primeira turma do curso de Licenciatura em Computação. Monografia (Graduação em Licenciatura em Computação) - Universidade Estadual da Paraíba, Patos, Paraíba.

Oliveira, Toni A. e Sousa, Jaeny P. (2005) "Licenciatura em Computação: Um Olhar Sobre o Processo de Formação do Licenciado na Universidade do Estado de Mato Grosso". Universidade do Estado de Mato Grosso (UNEMAT). In: Anais do evento IV Workshop em Educação em Computação e Informática do Estado de Minas Gerais (WEIMIG)/SBC, Varginha/MG,. Disponível em: 
http://www.weimig2005.unis.edu.br/artigos/Licenciatura\%20em\%20Computa\%E7\% E3o.pdf. Acesso em 27 de julho de 2013.

Priecht, S. S. e Pazeto, T. A. (2009). "Análise, Sugestões e Perspectivas de um Curso de Licenciatura em Informática". Anais do XVII Workshop sobre Educação em Informática. Disponível em: < http://www.lbd.dcc.ufmg.br/colecoes/wei/2009/019.pdf >. Acesso em 27 de julho de 2013.

Prietch, S. S. e Pazeto, T. A. (2010). "Estudo Sobre a Evasão em um Curso de Licenciatura em Informática e Considerações para Melhorias". WEIBASE, Maceió/AL. Disponível em: $<$ http://www.cesmac.com.br/erbase2010/papers/weibase/65258.pdf $>$. Acesso em 27 de julho de 2013.

Prietch, S. S. e Pazeto, T. A. (2010) "Mapeamento de Cursos de Licenciatura em Computação seguido de Proposta de Padronização de Matriz Curricular". In XVIII Workshop de Educação em Computação (WEI 2010), Anais do XXX Congresso da Sociedade Brasileira de Computação - CSBC 2010, pages 921-930.

Projeto Político Pedagógico do curso de Licenciatura em Computação. (2006). Disponível em https://docs.google.com/file/d/0B34jAqvG8BcZUhYMmdhRGhNclE/edit>. Acesso em 27 de julho de 2013.

Seabra, C. (2010) “Tecnologias na escola". Porto Alegre: Telos Empreendimentos Culturais. Disponível em < http://portaldoprofessor.mec.gov.br/storage/materiais/0000015325.pdf $>$. Acesso em 27 de julho de 2013.

Sette, S. S.; Aguiar, M. A. e Sette, J. S. A. (1997) "Licenciatura em Informática - uma questão em aberto". Revista Brasileira de Informática na Educação, vol.1, nov. de 1997. Disponível em: <http://bibliotecadigital.sbc.org.br/download.php?paper=928>. Acesso em 27 de julho de 2013.

Tajra, S. F. (2008) "Informática na Educação: novas ferramentas pedagógicas para o professor na atualidade”. 8 ed. São Paulo: Érica.

Tavares, N. R. B. (2002) "A história da informática educacional no Brasil observada a partir de três projetos públicos”. São Paulo: Escola do Futuro. Disponível em: < http://www.lapeq.fe.usp.br/textos/tics/ticspdf/neide.pdf>. Acesso em 27 de julho de 2013.

Valente, J. A. (s.d.) "Análise dos diferentes tipos de software usados na educação". In: O computador na sociedade do conhecimento. Brasília: Mec. Disponível em <http://ged.feevale.br/bibvirtual/Diversos/0000001A.pdf>. Acesso em 27 de julho de 2013.

Veen, W.; Vrakking, B. (2009) "Homo Zappiens: educando na era digital". Porto Alegre: Artmed. 